Colasurdo Diego (Orcid ID: 0000-0003-2899-5794)

\title{
Evidence of the presence of minor tautomeric forms in selected nitroanilines
}

Diego D. Colasurdo a, b, Matías N. Pila a, b, Sergio L. Laurella ${ }^{\text {a, c }}$, Patricia E. Allegretti a, c, Danila L. Ruiz ${ }^{\mathrm{a}, \mathrm{b}, *}$

${ }^{a}$ CEDECOR (UNLP-CICBA), Facultad de Ciencias Exactas, Universidad Nacional de la Plata, 47 esq. 115, 1900 La Plata, Argentina.

${ }^{\mathrm{b}}$ Consejo Nacional de Investigaciones Científicas y Técnicas CONICET, Argentina.

${ }^{\mathrm{c}}$ Comisión de Investigaciones Científicas de la provincia de Buenos Aires CICBA, Argentina.

*Corresponding author. E-mail: druiz@quimica.unlp.edu.ar

\section{ABSTRACT}

Rationale: Nitroanilines can exist in several tautomeric forms: nitro-amino, nitro-imino and aci-imino. The importance of the evaluation of minor tautomeric species comes from the fact that even less abundant tautomers have been proved to play important roles in reaction mechanisms.

Methods: Electron ionization mass spectra of the pesticide Pendimethalin and four related nitroanilines were recorded at $70 \mathrm{eV}$ in order to find information about the presence of minor tautomeric forms in the gas phase. The existence of the possible tautomers was evaluated by studying specific fragmentation pathways, which were confirmed by MS-MS experiments. Further supporting information was obtained by studying the structure of some intermediate compounds by theoretical calculations at the B3LYP 6-311++G(d,p) level.

Results: The pendimethalin mass spectrum suggests the coexistence of the nitro-amine tautomer (most stable form) with four possible less stable tautomers in equilibrium. The fragmentation routes were used to explain analogous peaks in two related compounds. However, the spectra of two other related compounds which cannot follow the proposed route of fragmentation for nitro-imine tautomers do not show the analogous peak. Theoretical

This article has been accepted for publication and undergone full peer review but has not been through the copyediting, typesetting, pagination and proofreading process which may lead to differences between this version and the Version of Record. Please cite this article as doi: $10.1002 / \mathrm{rcm} .9000$ 
calculations were used to correlate the precursor cation with the proposed fragmentation pathway.

Conclusions: By the study of mass spectra and proposed fragmentation pathways it can be concluded that, although the nitro-amine is the most abundant species within the system, minor tautomers (nitro-imine and aci-imine) coexist in the gas phase.

Keywords: Tautomerism; Mass spectrometry; Nitroanilines.

\section{Introduction}

The origins of the synthesis of nitro compounds date back to 1834, when Mitscherlisch synthesized nitrobenzene from benzene and fuming nitric acid. ${ }^{1}$ In 1845 , Hofmann and Muspratt systematized a process for the mono- and di-nitration of benzene. ${ }^{2}$ It is not common to find natural aromatic nitro compounds, and the first one to be isolated was chloramphenicol, in 1947. However, it was not until 1949 that Rebstock published its chemical structure and a possible way of synthesis. It was the first antibiotic isolated from a microorganism as well as the first synthetic one. ${ }^{3-4}$ Nitroanilines can be synthesized by ammonolysis of multinitrobenzenes, ${ }^{5}$ by acid hydrolysis of dinitroacetanilides ${ }^{6}$ and by nucleophilic aromatic substitution of the corresponding chloronitrobenzenes and amines. ${ }^{7}$ Many compounds of this family such as Oryzalin ${ }^{\circledR}$, Pendimethalin ${ }^{\circledR}$, Prodiamine ${ }^{\circledR}$ and Trifluarin ${ }^{\circledR}$ are used as herbicides to control grass and other weeds. ${ }^{8-10}$ Their mode of action involves the inhibition of root elongation by blocking tubulin production and producing mitosis interruption. ${ }^{11}$ Furthermore, Pendimethalin has been shown to cause a significant increase in both the mitotic index and the frequency of chromosomal aberrations for onion and corn plants. ${ }^{12}$

Nitro compounds can be involved in fast tautomeric equilibria, and nitro-aci tautomerism occurrence in aliphatic compounds is well known (Scheme 1). ${ }^{13}$ This tautomerism and many other have been studied in the gas phase by mass spectrometry, ${ }^{14}$ which has proved a powerful method for finding specific tautomers in these types of equilibria. ${ }^{15}$ However, there is no information in the literature on such tautomerism in solution and/or in aromatic nitro compounds.

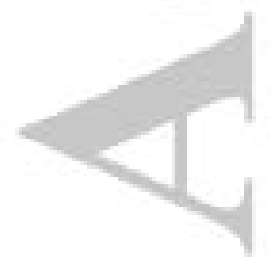

Scheme 1. Representation of nitro-aci tautomerism.

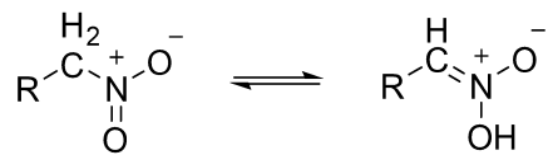


It is known that tautomers (even in minor forms) can play an important role within some reaction mechanisms. In the case of nitro-aci tautomerism, a nitronic acid tautomer form has been proposed as an intermediate in reactions of natural products, such as carbohydrates, thus showing that these tautomers behave as precursors of glucosinolates. ${ }^{16}$

The aim of the current study is to investigate the possibility of nitro-aci tautomerism in Pendimethalin and other $o$-nitroanilines, trying to ensure the existence of some minor tautomeric forms by the assignation of specific peaks in the electron ionization mass spectrum. Fragmentation pathways are confirmed by MS-MS experiments.

The combination of mass spectrometry and theoretical calculations has been widely used in our laboratory, with the conclusion that this is a powerful tool for the study of rapid equilibrium processes. ${ }^{17,18}$ Theoretical optimization of the tautomeric forms of Pendimethalin was performed using Gaussian software ${ }^{19}$ with the B3LYP level of theory and 6-31G(d,p) plus 6$311++\mathrm{G}(\mathrm{d}, \mathrm{p})$ as basis sets in order to support experimental data.

\section{Material and methods}

\subsection{Synthesis of nitroanilines}

Pendimethalin ${ }^{\circledR}\left(\mathrm{N}-\left[1\right.\right.$-ethylpropyl]-3,4-dimethyl-2,6-dinitrobenzenamine) (1) and Butralin ${ }^{\circledR}$ (2) were commercially available (Sigma-Aldrich, St. Louis, MO, USA). 4-[(1ethylpropyl)amino]-2-methyl-3,5-dinitrobenzyl alcohol (3) and 2,4,6-trinitro-N-methyl-aniline (4) were obtained by nucleophilic aromatic substitution of the corresponding chloronitrobenzenes and amines $;^{7}$ thus, (3) was obtained from (4-chloro-3,5dinitrophenyl)methanol and 2-butylamine, and (4) from picryl chloride and methylamine. The reaction was carried out by adding an excess of amines ethanol solution to a $5 \%$ ethanol solution of the chloride with stirring at room temperature. After 30-40 min ethanol was removed, acetone was added and filtered to remove the amine salt formed. By evaporation of acetone, the substitution product was obtained, which was then dried under vacuum and recrystallized with absolute ethanol. 4-(1,1-dimethylethyl)-N-(1-methylethyl)-2,6dinitrobenzenamine (5) was obtained by selective reduction. ${ }^{5}$

The yields obtained were 45, 52 and 39\% for compounds (3), (4) and (5), respectively. The products were identified by ${ }^{1} \mathrm{H}$ and ${ }^{13} \mathrm{C} \mathrm{NMR}$.

\subsection{Gas chromatography-mass spectrometry-single quadrupole}


Determinations were performed by injection of methanol solutions $(1 \mu \mathrm{L}, 0.1 \%)$ in an HP 6890 Chromatograph coupled to an Agilent/HP (Santa Clara, CA, USA) 5972A single quadrupole mass spectrometer. The analytical column was a HP5-MS (30 m x $0.25 \mathrm{~mm}$ x $5 \mu \mathrm{m}$ ). Helium was used as the carrier gas (flow rate of $0.6 \mathrm{~mL} / \mathrm{min}$ ). The temperatures were set at: $200{ }^{\circ} \mathrm{C}$ at the injector, $300{ }^{\circ} \mathrm{C}$ at the interface, $185^{\circ} \mathrm{C}$ at the ion source, and a $\mathrm{GC}$ oven temperature hed at $40{ }^{\circ} \mathrm{C}$ for $5 \mathrm{~min}$ and then ramped at $20{ }^{\circ} \mathrm{C} / \mathrm{min}$ to $290{ }^{\circ} \mathrm{C}$. Electron ionization analysis was performed with $70 \mathrm{eV}$ ionization energy. The low pressure in the mass spectrometer, $<10^{-5}$ torr, precludes ion-molecule reactions. There was no autoprotonation. There was no tautomer separation achieved in the experimental conditions used in this work.

\subsection{Gas Chromatography-Ion Trap Mass Spectrometry}

Determinations were performed by injection of methanol solutions in a ThermoQuest Trace 2000 gas chromatograph (Thermo Fisher Scientific, Waltham, MA, USA) coupled to a Finnigan Polaris ion trap mass spectrometer (Thermo Fisher Scientific) under the same experimental conditions as already mentioned for the single quadrupole GC/MS system. This instrumentation was utilized to confirm proposed fragmentation pathways by CID (collision induced dissociation) using helium as damping gas at a flow rate of $1.1 \mathrm{~mL} / \mathrm{min}$, a CID energy of $5-7 \mathrm{eV}$ and an excitation energy of $0.35-0.45 \mathrm{eV}$ (values were optimized for each ion transition). The ion trap temperature was kept at $200{ }^{\circ} \mathrm{C}$ for all experiments. The precursor ions were selected at $m / z, 207.0 \pm 0.5,253.0 \pm 0.5$ and 281.0 \pm 0.5 . In these three MS/MS experiments, the collision energy level (CEL) was 16\%, while the excitation time was $15 \mathrm{~ms}$.

\subsection{Theoretical calculations}

There are several computational procedures for treating tautomeric equilibria, with density functional theory (DFT) methods ${ }^{20}$ being preponderant over recent decades. The prediction of the tautomerism by quantum chemistry depends strongly on the DFT functional and basis set used. $^{21}$

All possible tautomers of the compounds under study were subjected to geometry optimizations using the DFT, for which B3LYP hybrid exchange-correlation ${ }^{22}$ together with the 6-31G(d,p) basis set as implemented in the Gaussian 03 package $^{19}$ was used. Numerous conformations were computed to ensure that the lowest energy conformation was obtained for each molecular system. All geometrical parameters were optimized without constraints. The minimum energy structures of drawn from these curves were re-optimized using the $6-311++G(d, p)$ basis set. 


\section{Results and discussion}

\subsection{Pendimethalin:}

2,5-Dinitroanilines could exist, as least at first, as five possible tautomers in equilibrium. These structures (named I-V from now on) are shown for Pendimethalin (1), which has been taken as the model in the present work, in Scheme 2.

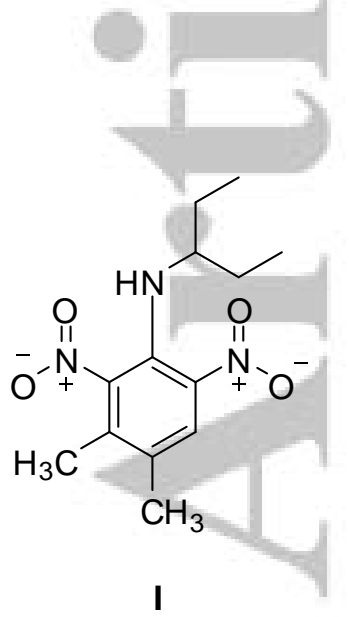

nitro-amine<smiles>CCC(CC)N=C1C([N+](=O)[O-])=CC(C)=C(C)C1[N+](=O)[O-]</smiles>

II<smiles>CCC(CC)N=C1C([N+](=O)[O-])=C(C)C(C)=C[C@H]1[N+](=O)[O-]</smiles>

III<smiles>CCC(CC)N=C1C([N+](=O)[O-])=CC(C)=C(C)C1=[N+]([O-])O</smiles>

IV<smiles>CCC(CC)N=C1C([N+](=O)[O-])=C(C)C(C)=CC1=[N+]([O-])O</smiles>

V

nitro-imine $A \quad$ nitro-imine $B$

aci-imine B

Figure 1 shows the mass spectrum of (1). There was no chromatographic separation of isomeric species. Thus, if there were more than one tautomeric form, the observed mass spectrum would be obtained from the combined spectra of all the overlapped species that arrive at the ionization source.

Figure 1. Mass spectrum of (1)

Two assumptions are generally made in this regard:

- Once radical cations (molecular ion included) are formed in the ion source, their tautomerization in the gas phase does not occur or can be ignored. The importance of this point comes from the physicochemical properties of ionic and radical species, which are quite different from those of neutral species. Since temperature effects are relevant to the determinations of enthalpy differences, both the sample introduction system (GC) and the ion source (MS) temperatures were varied to find evidence regarding the involvement of neutral or ionic species in the mass spectrometric results produced by tautomerism occurrence. For the studied compounds, no significant changes are observed when the ion source temperature was varied (data not shown). ${ }^{23}$ 
- Although it has been seen in exceptional cases for some families of compounds, ${ }^{24}$ chromatographic systems cannot separate tautomers.

This methodology has been proved successful in describing tautomeric species within a wide variety of systems. ${ }^{12-14,25-28}$

In order to determine which are the tautomeric forms that exist in equilibrium, a complete analysis of this spectrum has been made. The base peak of the spectrum at $m / z, 252$ can be explained from all the tautomeric forms (I-V) as being formed from an alpha cleavage after ionization on the basic nitrogen, as can be seen in Scheme 3 for tautomer I. Peaks at $m / z, 235$ and 189 are formed by characteristic neutral losses previously reported for nitro compounds. ${ }^{29}$

Scheme 3. Proposed fragmentation pathway from tautomer I to give peak at $m / z 252$.
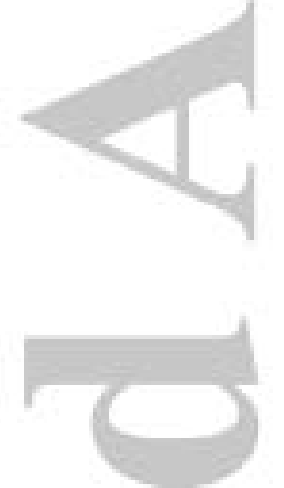

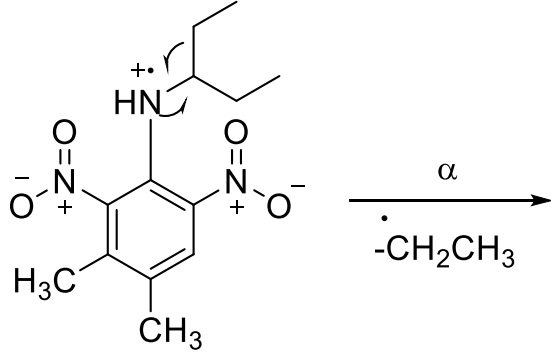

$\mathrm{m} / \mathrm{z} 281$<smiles>CC/C=[NH+]\c1c([N+](=O)[O-])cc(C)c(C)c1[N+](=O)[O-]</smiles>

$\mathrm{m} / \mathrm{z} 252$

The peak at $\mathrm{m} / \mathrm{z} 253$ can be formed from the molecular ion of tautomer $\mathbf{I}$ after a hydrogen rearrangement, as can be seen in Scheme 4.

Scheme 4. Proposed fragmentation pathway from tautomer I to give peak at $m / z 253$.

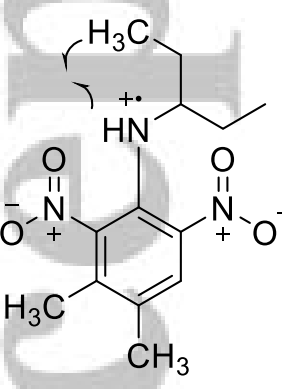

$\mathrm{m} / \mathrm{z} 281$

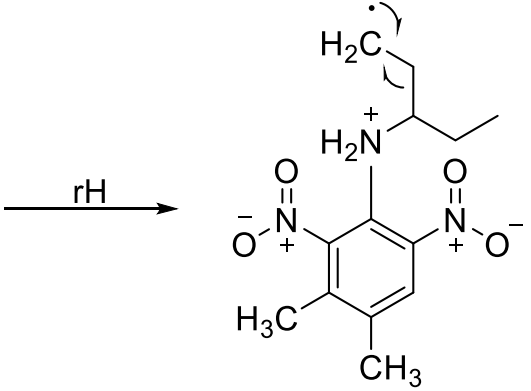

$\mathrm{m} / \mathrm{z} 281$<smiles>CCC[NH2+]c1c([N+](=O)[O-])cc(C)c(C)c1[N+](=O)[O-]</smiles>

$\mathrm{m} / \mathrm{z} 253$

The low abundance peak at $m / z 263$ is formed by loss of water from the molecular ion. This loss can be explained for Pendimethalin as involving a pericyclic elimination of water after a hydrogen rearrangement (Scheme 5 a). Compounds (2), (4) and (5) cannot follow this pathway 
but their spectra also show a peak at M-18. The formation of this ion could be explained in a general way as coming from the two minor aci-imino forms (tautomers IV and V) after a hydrogen rearrangement, as can be seen in Scheme $5 \mathrm{~b}$. It is important to note that even when a peak is of low abundance, the fact that it appears in the spectrum is strong evidence for the existence of the tautomeric forms from which it comes.

Scheme 5. Proposed fragmentation pathways from tautomer I (5 a) and $\mathbf{V}$ (can also be followed for IV) (5 b) to give peak at $\mathrm{m} / \mathrm{z} 263$.

a)<smiles>CCO[N+](=O)c1c(C)c(C)cc([N+](=O)[O-])c1NC(CC)CC</smiles>
$\mathrm{m} / \mathrm{z} 281$ $\mathrm{m} / \mathrm{z} 281$ b)

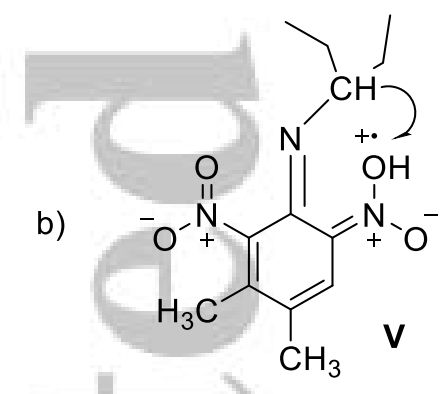<smiles>C/C=C\c1c(C)cc([N+](=O)[O-])c(NC(CC)CC)c1[N+](=O)[O-]</smiles>

$\mathrm{m} / \mathrm{z} 281$<smiles>CCC(C)(C)N=C1C([N+](=O)[O-])=C(C)C(C)=CC1=[N+]([O-])O</smiles>

m/z 281<smiles>C=C1C(C)=CC([N+](=O)[O-])=C(N=C(CC)CC)C1=[N+]=O</smiles>

$\mathrm{m} / \mathrm{z} 263$ 

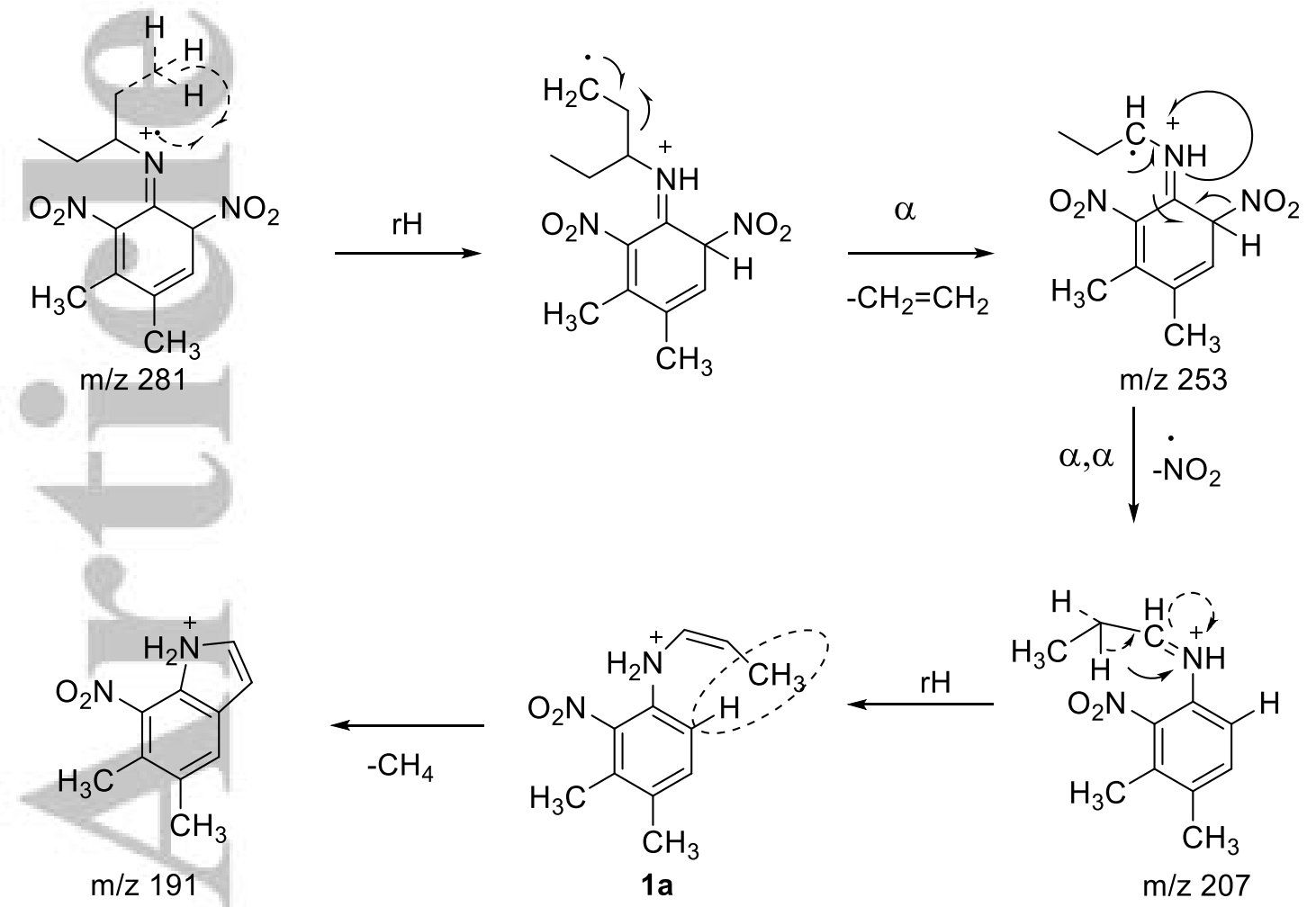

This pathway can only be proposed for tautomers II and III and it was confirmed by MS-MS experiments as can be seen in Table 1. Intermediate 1a can be obtained as the $\mathrm{E}$ or $\mathrm{Z}$ isomer, but only the $\mathrm{Z}$ isomer can follow the proposed and confirmed pathway. The neutral loss of methane as a small and stable molecule in order to form a compound that, after deprotonation, forms an indole derivative (another aromatic stable molecule) might act as driving force for this pathway.

The fragmentation pathways proposed in Schemes 4, 5 and 6 were confirmed by GC/Ion TrapMS experiments: ions at $\mathrm{m} / \mathrm{z} 252,253$ and 263 are generated from the molecular ion at $\mathrm{m} / \mathrm{z} 281$; the ion at $\mathrm{m} / \mathrm{z}, 207$ is formed from $\mathrm{m} / \mathrm{z}, 253$; and the ion at $\mathrm{m} / \mathrm{z} 191$ from the one at $\mathrm{m} / \mathrm{z} 207$. The results are summarized in Table 1.

\subsection{Other nitroanilines structurally related to Pendimethalin:}

The mass spectra of the nitroanilines shown in Scheme 7 have been investigated in order to confirm the fragmentation pathways proposed for (1). The mass spectra of Butralin (2), 4-[(1ethylpropyl)amino]-2-methyl-3,5-dinitrobenzyl alcohol (3), 2,4,6-trinitro-N-methylaniline (4) and 4-dimethylethyl-N-methylethyl-2,6-dinitroaniline (5) were analyzed. The fragmentation pathways proposed in Schemes 4-6 can be used to explain the analogous peaks in the spectra of (2) and (3), which are shown in Figures 2 and 3, respectively. All the results are summarized 
in Table 2. In the case of (2) there is also a peak at $\mathrm{m} / \mathrm{z}, 280$ which corresponds to the loss of $\mathrm{CH}_{3}$ following the same alpha cleavage that explains the peak at M-29 (compounds (1), (2) and (3)).

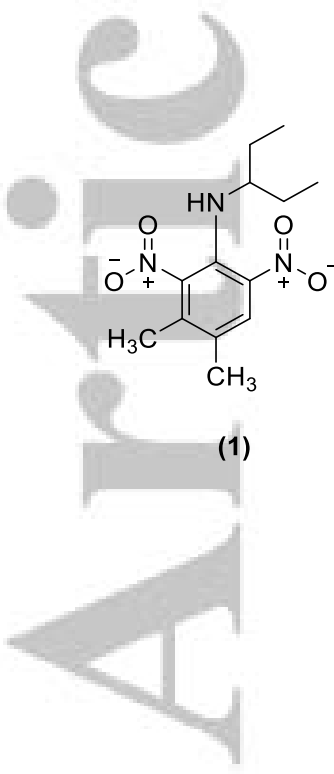

Scheme 7. Structure of analyzed nitroanilines.

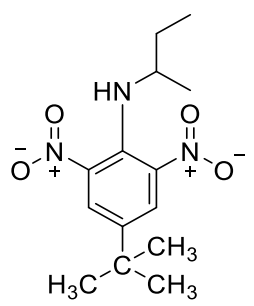

(2)<smiles>CCC(CC)Nc1c([N+](=O)[O-])cc(CO)c(C)c1[N+](=O)[O-]</smiles>

(3)<smiles>CNc1c([N+](=O)[O-])cc([N+](=O)[O-])cc1[N+](=O)[O-]</smiles>

(4)<smiles>CC(C)Nc1c([N+](=O)[O-])cc(C(C)(C)C)cc1[N+](=O)[O-]</smiles>

(5)

Figure 2. Mass spectrum of (2).

Figure 3. Mass spectrum of (3).

In order to find further evidence to confirm the pathway proposed in Scheme 6 for nitro-imine tautomer of (1), (2) and (3)), the spectra of the dinitroanilines (4) and (5) (which are unable to follow this pathway) were analyzed.

The spectrum of (4), which is shown in Figure 4, contains many peaks that can be explained as being formed from logical losses such as those at $m / z$ 225, 224 and 196, which correspond to the loss of $\mathrm{OH}, \mathrm{H}_{2} \mathrm{O}$ and $\mathrm{NO}_{2}$, respectively. The base peak can be explained as a loss of $\mathrm{HNO}_{2}$ followed by a loss of $\mathrm{H}$ by an $\alpha$ cleavage. It is necessary to highlight the absence of the peak at $\mathrm{m} / \mathrm{z} 152$ (M-90).

Figure 4. Mass spectrum of (4).

Figure 5 shows the spectrum of (5) in which many logical losses can be observed, such as the loss of a methyl group at $\mathrm{m} / z, 266, \mathrm{M}-\mathrm{H}_{2} \mathrm{O}$ at $\mathrm{m} / z, 263$ and $\mathrm{M}-\mathrm{NO}_{2}$-tertbutyl at $\mathrm{m} / \mathrm{z}, 178$. Once again, there is no M-90 peak at $\mathrm{m} / z, 191$

Figure 5. Mass spectrum of (5). 
Compounds (4) and (5) are unable to follow the fragmentation pathway proposed in Scheme 6 (despite having the same functional groups) due to the absence of a three-carbon-atom chain, which enables the cyclization in the final step. Therefore, the absence of a M-90 peak is expected.

\subsection{Theoretical calculations}

The relative stability of the five tautomers for (1) was calculated using Gaussian software with B3LYP method and 6-311++G(d,p) as basis set. The results are shown in Table 3. Tautomer I is the only aromatic tautomer and therefore it is, by far, the most stable structure. The relatively lower energy for tautomer II compared with tautomers III, IV and V can be explained by the decrease in steric repulsion between the nitro group and the methyl group when the carbon atom is $\mathrm{sp}^{3}$ hybridized. Although these calculations suggest that only tautomer I exists, they are gas-phase calculations and they can be different from condensed-phase results, so other tautomers might exist. For example, some nucleic acid bases have very different compositions in the gas phase from those in the solid state. ${ }^{30-31}$

Further supporting information was obtained by studying the structure of the intermediate 1a (Scheme 6) by theoretical calculations using Gaussian software, using the B3LYP functional and 6-311++G(d,p) as the basis set. As was previously pointed out, both (E and Z) isomers can be obtained, but only the $\mathrm{Z}$ 1a intermediate can lose $\mathrm{CH}_{4}$. The dihedral angle between the ring and the $\mathrm{NH}_{2} \mathrm{CHCHCH}_{3}$ group of this intermediate was varied and a local energy minimum was found when the methyl group approaches the hydrogen atom in the ring (Figure 6). This result supports the fragmentation pathway proposed in Scheme 6 and, therefore, the existence of tautomers II and III coexisting with I.

Figure 6. Local energy minimum conformation for compound 1a from Scheme 6.

\section{Conclusions}

The mass spectra of Pendimethalin (1) suggest the coexistence of the nitro-amino tautomer (most stable form) with four less stable possible tautomers in equilibrium (at least under the experimental conditions of this work). The nitro-amino and aci-imino tautomers (I, IV and V) explain most of the important peaks in the spectrum, but the peak at M-90 can only be explained as being formed from the nitro-imino tautomers II and III. This assumption was confirmed in several ways. At first, proposed fragmentation pathways were confirmed by MS-MS 
experiments. Then, all the pathways were used to explain analogous peaks in two related compounds, Butralin (2) and 4-[(1-ethylpropyl) amino]-2-methyl-3,5-dinitrobenzyl alcohol (3). In addition, the mass spectra of related compounds that cannot follow the fragmentation pathway proposed for tautomers II and III were studied and the lack of this peak was confirmed. Finally, theoretical calculations were carried out in order to find a correlation between the precursor cation and the last step of the pathway. A local energy minimum was found when the methyl group and the hydrogen that finally form the methane molecule that is lost are close each other.

\section{Conflicts of Interest}

The authors declare no conflicts of interest.

\section{Acknowledgements}

Authors acknowledge Facultad de Ciencias Exactas (Universidad Nacional de La Plata), Consejo Nacional de Investigaciones Científicas y Tecnológicas (CONICET), Comisión de Investigaciones Científicas de la Provincia de Buenos Aires (CICBA) and Agencia Nacional de Promoción Científica y Tecnológica (ANPCyT), República Argentina for financial support. S.L.L. and P.E.A. are member of the Scientific Researcher Career of CIC-BA and D.L.R. is member of the Scientific Researcher Career of CONICET.

\section{References}

1. Mitscherlich E. Ueber die Zusammensetzung des Nitrobenzids und Sulfobenzids. Ann Phys. 1834; 31: 625-631. doi: 10.1002/andp.18341074002

2. Muspratt JS, Hofmann AW. CXLI. On toluidine, a new organic base. Mem Proc Chem Soc. 1843; 2: 367. doi: 10.1039/MP8430200367

3. Rebstock MC, Crooks HM, Controulis J, Bartz QR. Chloramphenicol (Chloromycetin).1 IV.1a Chemical Studies. J Am Chem Soc. 1949; 71(7): 2458-2462. doi: 10.1021/ja01175a065

4. Gottlieb D. Antibiotics Vol 5. Part 1. Ch. 3. In: Hahn EF. Mechanism of Action of Antibacterial Agents. Springer, Berlin. 1979: 26-42.

5. Qianchao LJ, Xinzhi C. Preparation of Nitroanilines by Ammonolysis of Multinitrobenzenes. Synth Commun. 2008; 38: 2782-2786. doi: 10.1080/00397910701837412 6. Kijima A, Sekiguchi S. Alkaline hydrolyses of N-alkyl-2,4-dinitroacetanilides. J Chem Soc Perkin Trans 2. 1987; 9: 1203-1208. doi: 10.1039/P29870001203 
7. Buncel E, Norris AR, Russell KE, Sherid PJ. Kinetic and Thermodynamic Studies of the Reactions of Sulfite Ion with Picramide, N-Methylpicramide, and N,N-Dimethylpicramide in Aqueous Solution. Can J Chem. 1974; 52:25-33. doi: 10.1139/v74-004

8. Smith DT, Richard EP, Santo LT Jr. In: The Triazine Herbicides. LeBaron HM, McFarland JE, Burnside OC. Elsevier. 2008:185-197.

9. Association of Applied Biologists (AAB) Wellesbourne Warwick. The value of preemergence herbicides for combating herbicide-resistant alopecurus myosuroides (black-grass). 2009.

https://repository.rothamsted.ac.uk/item/8q314/the-value-of-pre-emergence-herbicides-forcombating-herbicide-resistant-alopecurus-myosuroides-black-grass

10. Endeshaw MM, Li C, de Leon J, et al. Synthesis and evaluation of Oryzalin analogs against Toxoplasma gondii. Bioorg Med Chem Lett. 2010; 20(17): 5179-5183. doi: 10.1016/j.bmcl.2010.07.003

11. Benbow JW, Bernberg EL, Korda A, Mead JR. Synthesis and Evaluation of Dinitroanilines for Treatment of Cryptosporidiosis. Antimicrob Agents Chemother. 1998; 42(2): 339-343. PMID: 9527782

12. Promkaew N, Soontornchainaksaeng P, Jampatong S, Rojanavipart P. Toxicity and Genotoxicity of Pendimethalin in Maize and Onion Nuttapol. Kasetsart J. Nat Sci. 2010; 44: 1010-1015.

13. Ruiz DL, Laurella SL, Cortizo MS, et al. Mass spectrometric study and theoretical calculations on the tautomerism of nitrocompound-nitronic acid. Trends Org Chem. 2010; 14: 63-71.

14. Allegretti PE, Colasurdo DD, Pila MN, Laurella SL, Ruiz DL. Estudio de Equilibrios Tautoméricos por Espectrometría de Masa. Académica española. 2018.

15. Colasurdo DD, Pila MN, Iglesias DA, Laurella SL, Ruiz DL. Tautomerism of uracil and related compounds: A mass spectrometry study. Eur J Mass Spectrom. 2018; 24(2): 214-224. doi: $10.1177 / 1469066717712461$

16. Matsuo M, Kirkland DF, Underhill EW. 1-Nitro-2-phenylethane, a possible intermediate in the biosynthesis of benzylglucosinolate. Phytochem. 1972; 11: 697-701. doi: 10.1016/00319422(72)80034-7

17. Allegretti PE, Asens D, Schiavoni MM, Bravo RD, Castro EA, Furlong JJP. Mass spectral and theoretical studies on the tautomerism of selected thioesters. Arkivoc. 2003; 15: 134-142. doi: 10.3998/ark.5550190.0004.f15 
18. Furlong JJP, Schiavoni MM, Castro EA, Allegretti PE. Mass spectrometry as a tool for studying tautomerism. Russ J Org Chem. 2008; 12: 1725-1736. doi: $10.1134 / \mathrm{S} 1070428008120014$

19. Frisch MJ, Trucks GW, Schlegel HB, et al. Gaussian 03, Revision C.02. Gaussian, Inc., Wallingford CT. 2004.

20. Parr RG, Yang W. Density functional theory of atoms and molecules. Oxford University Press, New York. 1989.

21. Antonov L. Tautomerism: methods and theories. Wiley-VCH, Weinheim. 2014.

22. Becke AD. A new mixing of Hartree-Fock and local density-functional theories. $J$ Chem Phys. 1993; 98: 1372. doi: 10.1063/1.464304

23. Allegretti PE, Milazzo CB, Furlong JJP. Mass spectrometry as a tool for the determination of heats of tautomerization of thioamides in the gas phase. Eur J Mass Spectrom. 2005; 11: 53. doi: $10.1255 /$ ejms.691

24. Allegretti PE, Schiavoni MM, Di Loreto HE, Furlong JJP, Della Védova CO. Separation of keto-enol tautomers in $\beta$-ketoesters: a gas chromatography-mass spectrometric study. $J \mathrm{Mol}$ Struct. 2001; 560: 327-335. doi: 10.1016/S0022-2860(00)00773-0

25. Allegretti PE, Schiavoni MM, Guzman C, Ponzinibbio A, Furlong JJP. Mass spectral study of the occurrence of tautomeric forms of thiohydantoins. Eur J Mass Spectrom. 2007; 3: 291. doi: $10.1255 /$ ejms. 885

26. Saraví Cisneros H, Erben M, Della Vedova CO, Laurella SL, Allegretti PE, Furlong JJP. Determination of Heats of Tautomerization of Nitrile-Ketenimine by Mass Spectrometry. Eur J Mass Spectrom. 2011; 17: 125-143. doi: 10.1255/ejms.1112

27. Ruiz DL, Schiavoni MM, Laurella SL, Giussi JM, Furlong JJP, Allegretti PE. The evidence for the occurrence of tautomeric structures for selected aldehydes and thioaldehydes. Spectrochim Acta Part A. 2011; 78: 1397-1402. doi: 10.1016/j.saa.2011.01.017

28. Ruiz DL, Spaltro A, Caputo M, Iglesias DA, Allegretti PE. Mass spectral study of the occurrence of tautomeric forms of selected enaminones. Int J Mass Spectrom. 2015; 379: 8796. doi: 10.1016/j.ijms.2014.12.010

29. Egsgaard H, Carlsen L. Mass Spectrometry of Nitro and Nitroso Compounds. In: Rappoport Z, Patai S. The Chemistry of Amino, Nitroso, Nitro and Related Groups. Wiley: Chichester. 1996: 249-294.

30. Yang Z, Rodgers MT. Theoretical studies of the unimolecular and bimolecular tautomerization of cytosine. Phys Chem Chem.Phys. 2004; 6: 2749-2757.

doi: 10.1039/B315089E

This article is protected by copyright. All rights reserved. 
31. Belova NV, Oberhammer H, Trang NH, Girichev GV. Tautomeric properties and gas-phase structure of acetylacetone. J Org Chem. 2014; 7912, 5412-5419.

doi: $10.1021 /$ jo402814c

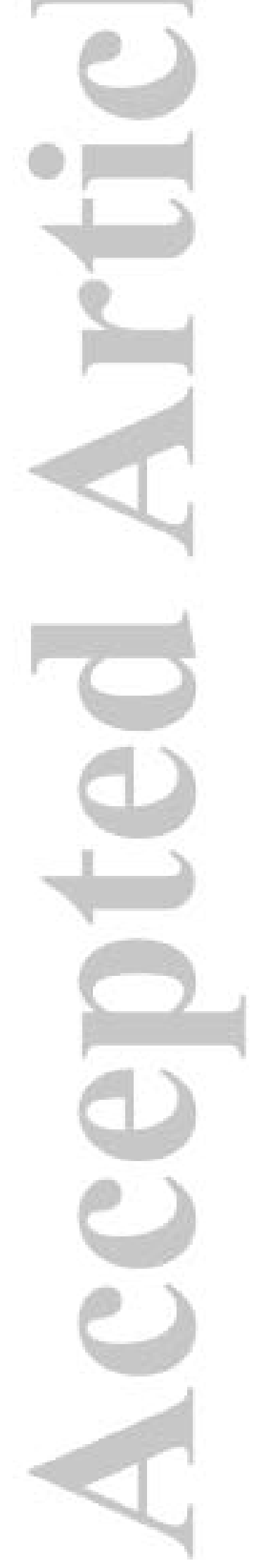

This article is protected by copyright. All rights reserved. 
Table 1. MS-MS Data for (1).

\begin{tabular}{cc}
\hline Precursor Ion $(\mathrm{m} / \mathrm{z})$ & $\begin{array}{c}\text { Relevant Product Ions } \\
(\mathrm{m} / \mathrm{z})\end{array}$ \\
\hline 281 & $252,253,263$ \\
253 & 207 \\
207 & 191 \\
\hline
\end{tabular}

Table 2. Analogous peaks for (2) and (3) following the same fragmentation pathways as proposed for (1).

\begin{tabular}{cccc}
\hline Analogous peak & $\begin{array}{c}(\mathbf{1}) \\
(\mathbf{m} / \mathbf{z})\end{array}$ & $\begin{array}{c}(\mathbf{2}) \\
(\mathrm{m} / \boldsymbol{z})\end{array}$ & $\begin{array}{c}(\mathbf{3}) \\
(\mathrm{m} / \boldsymbol{z})\end{array}$ \\
\hline$[\mathrm{M}]^{+\cdot}$ & 281 & 295 & 297 \\
{$\left[\mathrm{M}-\mathrm{CH}_{2}-\mathrm{CH}_{3}\right]^{+}$} & 252 & 266 & 268 \\
{$\left[\mathrm{M}-\mathrm{CH}_{2}=\mathrm{CH}_{2}\right]^{+.}$} & 253 & 267 & 269 \\
{$\left[\mathrm{M}-\mathrm{CH}_{2}=\mathrm{CH}_{2}-\mathrm{NO}_{2}-\mathrm{CH}_{4}\right]^{+}$} & 191 & 205 & 207 \\
\hline
\end{tabular}

Table 3. Relative stability of tautomers I-V for compound (1).

\begin{tabular}{cc}
\hline Tautomer & $\begin{array}{c}\text { Relative energy } \\
(\mathrm{kcal} / \mathrm{mol})\end{array}$ \\
\hline I & 0 \\
II & 27.85 \\
III & 33.37 \\
IV & 32.36 \\
V & 133.39 \\
\hline
\end{tabular}

